Abortion, birth defects/genetic disorders 65 Anxiety 196

Apolipoprotein E 202

Azores, Machado-Joseph disease 196

\section{Bioethics 176}

Biological sample, genetic databases 173

Biotechnology 176

Birth defects 76, 95, 111

- prevalence 76

Brazil, clinical genetics 95

Chile, genetic services 121

Clinical genetics 95, 106

Colombia, genetic services 126

Concerns, genetic research 44

Congenital anomalies 130, 146

Cuba, genetic services 130

Data protection 173

Depression 196

Down syndrome, postnatal diagnosis (age) 55

\section{Education 150}

Environmental risk factors, congenital malformations 76

Epidemiology, methodological considerations 161

Ethnicity 44

Family communication 15,25

- history, genetic conditions 161

Focus group methodology 185

- - sessions, ethnicity 44

Folic acid 121
Genetic conditions 161

- counseling 15,65, 130, 196

- database 173

- discrimination 161

- diseases 95

- health 137

- risk(s), congenital malformations 76

- - family communication 15

Geneticist-linguist interaction, research strategies 2

Health policies 111,137

Home delivery, Down syndrome diagnosis 55

Hospital network 76

Human rights 173

Languages 2

Latin-American human genetics network 74

Law, biotechnology 176

Lay understanding, race 185

Machado-Joseph disease 196

- - at-risk individuals, anxiety/depression levels 196

Marfan syndrome 216

Methodology, genetic discrimination 161

Mexico, genetic services 142

Minas Gerais, genetic/health services 117

Molecular markers, congenital malformations 76

Neural tube defects 130

Newborn screening 121, 146

Older adults, personal characteristics 202
Paraguay, genetic services 146

Peru, medical genetics 150

Policy approaches, rethinking 176

Population history, genes/language 2

Predictive testing, Machado-Joseph disease 196

Primary health care, developing countries 70

Quality of life, Marfan syndrome 216

Questionnaire study, patient perceptions 216

Race 185,202

Regional network, medical genetics 157

Risk factors, congenital malformations 76

Sanitary conditions, Peru 150

Secular trends 76

Severity, Marfan syndrome 216

Sickle cell disorders 130

Social support 25

Stigmatization, Machado-Joseph disease 196

Support groups, community resources 150

Teledysmorphology service 121

$\alpha$-Thalassaemia, community profile (Western Australia) 211

Western Australia, $\alpha$-thalassaemia 211

World Health Organization, community genetic services recommendations 157

Zulia (Venezuela), medical genetics 153

\section{KARGER}

(c) 2004 S. Karger AG, Basel

Fax + 41613061234

E-Mail karger@karger.ch www.karger.com
Accessible online at: www. karger.com/cmg 